\title{
The Effect of the Northeast Dairy Compact on Producers and Consumers, with Implications of Compact Contagion
}

\author{
Joseph V. Balagtas and Daniel A. Sumner* \\ Department of Agricultural and Resource Economics \\ University of California, Davis \\ Davis, California 95616 \\ Phone: (530) 752-1668 \\ Email: dasumner@ucdavis.edu
}

*We thank Henrik Olesen and Himawan Hariyoga for contributions and Tom Gossard and Eric Erba for comments in the early stages of this research. Compact data was provided by David Ferch of the Compact Commission. 


\section{The Effect of the Northeast Dairy Compact on Producers and Consumers, with Implications of Compact Contagion}

There is a long history of federal and state regulation of the United States dairy industry, dating back to Depression-era programs. Since the 1930s federal and state government involvement in the dairy industry has consisted of four major components: (i) a federal price support program that supports a target minimum farm price of milk with purchases of manufactured dairy products; (ii) federal border measures comprised of export subsidies and import barriers; (iii) federal and state marketing order systems that regulate raw milk prices and supplies regionally; (iv) federal and state food safety and sanitation regulations (Blaney, et al.; Bailey (1997); Manchester; Erba and Novakovic; Sumner and Cox). While the programs have each evolved since the 1930s, these main policy instruments remain largely intact today.

The recent development of the Northeast Interstate Dairy Compact (hereafter Northeast Compact or Compact) adds a new element to milk pricing in the United States. The Compact has potentially important implications for dairy policy in the U.S. and, in particular, for the pricing of raw milk through the Federal Milk Marketing Order (FMMO) system. In effect, the Northeast Compact allows one group of producers to be both within and outside the government-sponsored milk cartel that is the FMMO system. The Northeast Compact raises the price paid to Northeast producers thus increasing production and lowering the milk price received by other cartel members and those producers who do not participate in the cartel.

Several authors have examined aspects of the Northeast Compact. Bailey (1999 and 2000) and U.S. OMB use the standard model of price discrimination (Ippolito and 
Masson) to reason that the Compact would raise revenues for Northeast producers and find that this reasoning is consistent with the data. Nicholson provides econometric evidence that the Compact encourages increased milk supply from the Northeast region. Wackernagel uses a farm simulation model to show that, by raising the farm price of milk and lowering price variability, the Compact improves the financial performance of a representative Vermont dairy farm.

This paper is the first to lay out in an explicit and consistent framework the quantitative effects of the Northeast Compact on producers and consumers. We model and measure the Northeast Compact's effects on milk markets throughout the United States. Unlike previous studies, we model the FMMO pricing policy, which we use as our counter-factual scenario against which we measure the Compacts effects. Further, our welfare analysis considers not only producers and consumers within the Compact region, but those outside of the Compact region. This paper goes beyond the immediate effects of the current Compact to consider the potential welfare implications of "Compact contagion". We also consider implications for FMMO cartel stability.

As expected, and as our analysis shows, Northeast producers-who produce a relatively small portion of the nation's milk—have a correspondingly small effect on national milk prices. Nonetheless, the Compact has been controversial, in part because it raises the opportunity for other states to possibly join the Northeast Compact or establish new compacts. We show that a larger Compact (or more compacts) would have much greater influence on milk markets throughout the country. Further, we argue that independent, regional administration of classified prices can lead to the breakdown of the FMMO milk cartel, which has lasted for more than sixty years. 


\section{Milk Marketing Orders}

Milk marketing orders set minimum prices that may be paid for fluid eligible (Grade A) milk according to how that milk is used (classified pricing). The minimum price for milk used in hard dairy products (Class III or IIIa) in all federal orders is set administratively according to a formula, which takes account of the price of unregulated Grade B milk (eligible for manufacturing purposes only) in the Minnesota-Wisconsin region and the price of hard dairy products. The minimum price for milk used in fluid products (Class I) in each order is set as a fixed differential over the Class III price. These administratively determined fluid differentials are not uniform across orders, but generally increase with an order's distance from Wisconsin. Each marketing order also pools milk revenues and pays a uniform, weighted average price of all milk sold in that market to individual farmers delivering milk to that order (Blaney, et al.; Bailey (1997); Erba and Novakovic; Sumner and Cox; USDA-AMS). The producer, or blend, price in any order depends not only on the classified prices but also on the utilization rates of the various milk classes, which also vary from order to order. Thus, producer prices vary across orders.

The FMMO system operates likes a government-sponsored price-discriminating milk cartel in that it determines the pattern of milk prices across much of the country. (Early analysis was by Kessell; Kwoka; and Ippolito and Masson. More recent work is in Dahlgran; Helmberger and Chen; and Sumner and Cox.) This cartel raises prices for fluid milk consumers in each order and raises the average price received by dairy farmers. By establishing a pattern of producer prices that vary across regions the FMMO 
system creates potential for arbitrage, but preserves the regional pattern of prices with disincentives to ship milk between regions (even as the cost of shipping bulk milk has fallen over time). This system has endured for more than sixty years in part because centralized administration and enforcement of the classified pricing system has reduced the problem of "cheating", which the economics of oligopoly tells us makes many such arrangements difficult to sustain (Stigler 1964; Stigler 1975).

Most major milk markets are covered by the federal system of marketing orders. In 1998 about two-thirds of the Grade A milk produced in the country was regulated by the FMMO system. Of those markets not covered by the federal system, most belong to a state order. Of the state marketing orders, California is the most important, producing about $18 \%$ of the country's Grade A milk. California's pricing mechanism differs from that of the FMMO, but the differences are not crucial for our analysis here. Sumner and Wilson document the development of the California system, and Sumner and Wolf model the difference between California and federal milk marketing orders.

\section{The Northeast Dairy Compact}

With approval from Congress and the USDA, the New England state legislatures granted the Compact Commission authority to regulate the minimum fluid use (Class 1) price within the region starting in July $1997^{1}$. The Compact's regulatory rules work in conjunction with the New England FMMO, based in Boston, Massachusetts. The Compact sets a fixed minimum price (as opposed to a fluid differential) for Class 1 milk

\footnotetext{
${ }^{1}$ The Compact system also passed federal district court challenges brought by processor groups in January 1998 and again in November 1998 (Northeast Dairy Compact Commission).
} 
for the Northeast region. Thus the effective minimum price for Class 1 milk in that region is the greater of the Compact minimum price and the FMMO announced Class 1 price in the New England order. The Class 1 price that has been determined to be acceptable - by two-thirds vote of New England state delegations, and by producer referendum—is $\$ 16.94$ per hundredweight of milk (cwt). If the FMMO minimum Class 1 price in a particular month falls below $\$ 16.94$ processors are obligated to pay the difference to the Compact Commission. The Commission, in turn, distributes the revenue back to producers ${ }^{2}$. For detailed discussion of Compact history and rules, see Bailey (2000), Alexander et al., and the Northeast Dairy Compact Commission.

\section{Qualitative Implications for Prices and Welfare}

The Northeast Compact effectively avoids the pricing rules of the FMMO cartel by administering a fluid class milk price independent of the FMMO pricing system, thereby raising the average producer price for Northeast dairy farms. As a result, fluid milk consumers in that region face higher milk prices. Dairy farms outside of the Northeast region lose, since the higher producer price in the Northeast raises the level of milk production in that region and lowers the price of milk for producers throughout the rest of the country.

\footnotetext{
${ }^{2}$ Payments to producers are made only after adjustments are made to reimburse the Women Infants and Children program, school lunch programs, and other government outlays that may increase due to a higher milk price caused by the Compact. In approving the Compact, Congress did not hold the Commission responsible for a similar compensation to private consumers of fluid milk. See Wang, et al. for the effects of the Compact on WIC.
} 
It is not surprising then that the Compact has faced controversy on two fronts. By raising Class 1 prices, the Compact transfers income from milk consumers to dairy farms in the Northeast. The transfer can also be seen as a payment from relatively populous states, such as Massachusetts, to relatively rural, dairy-oriented states, such as Vermont. Indeed, it was such an interpretation that prompted the Massachusetts state legislature to consider seriously the possibility of withdrawing from the Compact.

The Compact is also controversial because of the effect such an institution can have on milk markets outside of the Compact region. As our results show, the Compact has the ability to raise the producer price in the Northeast, which brings forth increased milk production from the region. Under classified pricing, additional production is allocated to the manufacturing milk market, which lowers milk prices for producers throughout the country.

Because the Northeast region produces a relatively small portion of the country's milk, the Northeast compact has a relatively small effect on the price of manufacturing milk. However, dairy farms in other regions have the same incentive as Northeast producers to "cheat" the FMMO milk cartel. Note, since the FMMO cartel does not limit total output, cheating does not take the form of increased production as in a supplylimiting cartel. Rather, cheating in this case takes the form of a region raising the price for the local, inelastic demand market. If other states join the Northeast Compact or form similar regional compacts—-that is to say, if more and more producers cheat the FMMO cartel—the costs imposed on fluid milk consumers and non-compact producers will rise. Further, the potential for local administration of independent, regional classified prices raises questions about the continued sustainability of a national milk cartel. 
We now model quantitatively the Northeast Compact and its effect on various producer consumer groups and parameterize the model and measure these effects. In a later section, we use the model to illustrate the effect of an expanded dairy compact or additional regional compacts.

\section{A Quantitative Model of the Effects of the Compact}

Ippolito and Masson developed a model of regulated milk markets, building on Kessel's model of discriminatory pricing by the FMMO system. As with many intervening articles (Blaney et al.; Kwoka; Dahlgran; Cox and Sumner; and Sumner and Wolf, among others), we use this general framework to model the Northeast milk market, and to analyze the effects of the Dairy Compact. Like these previous authors, we assume locally linear supply and demand throughout the paper. Our results would be similar under a constant elasticity specification.

We assume for simplicity that the FMMO system distinguishes between two enduse classes of Grade A milk. Milk used in fluid products is designated Class f, while milk used in manufactured products is designated Class $\mathrm{m}$. Due to cost of shipping bottled milk and FMMO regulations that restrict the movement of milk across regions, the demand for Class f milk facing Northeast producers is regional and relatively inelastic. Manufactured dairy products are traded across the country; thus we use a national demand curve for Class m milk. Since the Northeast produces only a small fraction of the country's manufacturing milk, the portion of the demand for Class m milk facing Northeast producers is relatively elastic. Assuming linearity, we can write the regional demand curves as 
manufacturing demand : $D_{m}\left(P_{m}\right)=\alpha_{0}-\alpha_{1} P_{m}$

fluid demand : $D_{f}\left(P_{f}\right)=\beta_{0}-\beta_{1}\left(P_{f}\right)$

$$
\alpha_{0}, \alpha_{1}, \beta_{0}, \beta_{1}>0
$$

where the subscripts $f$ and $m$ denote the fluid and manufacturing markets, respectively.

The supply of Grade A milk in the Northeast can be expressed as

$$
\begin{gathered}
Q^{s}(P)=\delta_{0}+\delta_{1} P \\
\delta_{1}>0
\end{gathered} .
$$

This schedule represents supply from all Grade A producers-whether located in or outside of the Compact region-who deliver Grade A milk to processors regulated by the New England FMMO.

In the absence of the Compact, we assume all Grade A milk in the region would be sold at the minimum prices set by the New England FMMO. The marketing order sets a fixed fluid differential, $\mathrm{d}$, so that the price paid for fluid milk is

$$
P_{f} \equiv P_{m}+d,
$$

and that the price paid for manufacturing milk, $P_{m}$, is determined by a competitive market. All producers delivering milk in this region receive a uniform, weighted average (blend) price ${ }^{3}$ determined by

\footnotetext{
${ }^{3}$ As with the other literature on milk marketing orders, we ignore over-order premiums here. Inclusion of over-order premiums would not change our analysis significantly, and the direction of the Compact's effects would be the same as found here, as long as the Compact Class $\mathrm{f}$ price is set above the price that would have been paid for Class $f$ milk. To the extent that over-order premiums are paid in the absence of the Compact, our results will overestimate the increase in the Class $\mathrm{f}$ price due to the Compact.
} 


$$
\begin{aligned}
P_{b}\left(P_{m} ; d\right) & =\frac{D_{f}\left(P_{m}+d\right)+D_{m} P_{m}}{D_{f}+D_{m}} \\
& =P_{m}+\frac{D_{f}}{D_{f}+D_{m}} d,
\end{aligned}
$$

which asymptotically approaches aggregate demand curve under the fixed differential policy, $D_{f}\left(P_{m}+d\right)+D_{m}\left(P_{m}\right)$, as $P_{m}$ falls and an increasing share of milk is sold as Class $m$.

Equilibrium in this market is illustrated in Figure 1. The blend price and total quantity of milk sold are determined by the intersection of the blend price curve and the supply curve. Given this supply, the price for manufacturing milk, labeled $\mathrm{P}_{\mathrm{m}}{ }^{*}$, is read off of the Grade A milk demand curve. The marketing order sets the fluid price at $\mathrm{P}_{\mathrm{f}}^{*}=\mathrm{P}_{\mathrm{m}}{ }^{*}+\mathrm{d}$, at which price fluid demand is $\mathrm{D}_{\mathrm{f}}\left(\mathrm{P}_{\mathrm{f}}^{*}\right)$. The quantity of manufacturing milk is the difference between supply and fluid demand.

Unlike the FMMO, the Compact sets a fluid price directly (as opposed to setting a differential) such that the fluid price under the Compact is no lower, and often higher, than the price set by the marketing order. The Compact thus raises the minimum price of Class $\mathrm{f}$ milk and transfers the additional revenues to producers. If the Compact sets a minimum Class $f$ price at $\mathrm{P}_{c}$, the effective minimum price becomes $\max \left(\mathrm{P}_{c}, \mathrm{P}_{\mathrm{f}}\right)$. Assuming that the Compact sets the fluid price such that $\mathrm{P}_{\mathrm{c}}>\mathrm{P}_{\mathrm{f}}$, the aggregate demand for milk becomes $\mathrm{D}_{\mathrm{f}}\left(\mathrm{P}_{\mathrm{c}}\right)+\mathrm{D}_{\mathrm{m}}\left(\mathrm{P}_{\mathrm{m}}\right)$ where the fluid demand and price are now fixed, and all additional production (beyond fluid demand) in this region is sold in the Class m market. Notice that under the milk marketing order, additional milk production lowers $\mathrm{P}_{\mathrm{m}}$, which in turn lowers $\mathrm{P}_{\mathrm{f}}$ and raises the demand for fluid milk. Thus, under the Compact's fixed fluid price Northeast producers have more influence on the price of manufacturing milk (assuming that the demand for fluid milk is less than perfectly inelastic). 
The blend price paid to producers under the Compact pricing rule is

$$
P_{b}\left(P_{m} ; P_{c}\right)=\frac{D_{f} P_{c}+D_{m} P_{m}}{D_{f}+D_{m}}
$$

which asymptotically approaches the aggregate demand curve under the fixed Class $\mathrm{f}$ price policy $\mathrm{P}_{\mathrm{m}}$ falls and an increasing share of milk is sold as Class $\mathrm{m}$. This was also the case under the FMMO pricing scheme, but, as we just noted, aggregate demand is different under the two regimes.

Figure 2 illustrates the effects of a higher fluid price due to the Compact, with subscript $\mathrm{c}$ denoting the prices and quantities under the Compact regime and the relevant blend curve and demand schedule in bold. If the Compact sets $\mathrm{P}_{\mathrm{c}}>\mathrm{P}_{\mathrm{f}}$, less Class $\mathrm{f}$ milk is sold under the Compact regime. The blend price line thus shifts upwards and intersects the supply schedule at a higher price than the FMMO blend price (blend prices not labeled). The blend price approaches the aggregate demand for milk at a faster rate under the Compact regime since fluid demand is fixed. The higher blend price encourages an expansion in the milk supply along the supply schedule. With more milk supplied and less milk used in Class $\mathrm{f}$, the supply of Class m milk from the Northeast expands relative to the FMMO equilibrium of Figure 1, lowering the price for manufacturing milk.

By raising the blend price in the Compact region, the Compact raises the revenues of the Northeast's farms (and of other farms that ship milk to Compact region handlers). Additional producer revenues come at the expense of fluid milk consumers, who must pay higher prices. The loss in fluid milk consumer surplus due to the Compact can be seen in Figure 2 as the area to the left of the fluid demand curve, and between the Compact and FMMO minimum Class f prices. 
The effect of the Compact on producers and consumers in other regions works through the lower price of manufacturing milk caused by an expansion in the Northeast's Class $\mathrm{m}$ sales. As more manufactured milk products are produced and sold on the national market, the price for Class $\mathrm{m}$ milk throughout the country is driven lower, as are Class $f$ prices in other marketing orders due to the Class $m$ plus differential formulas used to obtain Class $\mathrm{f}$ minimum prices. Faced with lower producer prices, milk supply in nonCompact regions contracts ${ }^{4}$. On the other hand, consumers of manufactured dairy products, and consumers of fluid milk outside of the Compact enjoy lower prices.

From the model, it is clear that the Compact's effect on producers and consumers outside of the Compact region depends on Compact producers' ability to affect the prices in the manufacturing milk market. Were the Compact's share of the manufacturing market to grow—either through the addition of states to the Northeast Compact or through the formation of new regional dairy compacts—-the effect on national milk prices would also grow.

In the following section, we parameterize the model and estimate the effect of the Compact on prices, quantities and producer and consumer welfare. We then explore the possibility of Compact contagion — growth of the Compact to include a larger share of national milk production.

\footnotetext{
${ }^{4}$ The lower manufacturing price has a similar effect on producers of manufacturing grade (Grade B) milk, including those located within the Northeast region, since Grade B and Class m milk are substitutes in manufactured dairy products. This also applies to Grade A producers who are outside both federal and state marketing orders.
} 


\section{Measures of Policy Incidence}

We measure the effects of the Compact on the various producer and consumer groups relative to a scenario that would prevail in the absence of the Compact. We assume that the class and blend prices announced by the New England FMMO would be relevant in the absence of the Compact, and measure by simulation the price, quantity and welfare effects of eliminating the Compact.

We parameterize the linear supply and demand model of Figure 2 using annual milk marketing data and supply and demand elasticities drawn from the agricultural economics literature. We use the most recent year with available data, 1999, as a base year for our simulations ${ }^{5}$. The data used to parameterize the model consists of annual quantities and annual average prices of Class 1 milk and all milk published by the USDA and the Compact Commission; these are used to impute prices and quantities of manufacturing milk. The data are listed in Table 1. Statistics for the entire FMMO system are also included in Table 1 for comparison ${ }^{6}$.

A range of farm-level milk supply elasticities can be found in the agricultural economics literature. We consider an intermediate time horizon of 3 to 6 years to allow

\footnotetext{
${ }^{5}$ The specific numerical results depend on our choice of base year. We use the most recent data. The Compact played less of a role in 1998 due to higher FMMO prices. Thus, had we used 1998 as a base year, the magnitude of effects of the Compact discussed here would be smaller. However, the direction of the price, quantity, and welfare effects do not depend on the base year.

${ }^{6}$ Note that we use annual quantities and average annual prices, while the FMMO and the Compact both set monthly prices. The monthly fluid class price announced for the New England FMMO actually exceeded $\$ 16.94$ in five months in 1999. Since the Compact's minimum price is $\max (\$ 16.94$, FMMO Class 1 price $)$, the average annual Compact price actually exceeded \$16.94 in 1999.
} 
for adjustments in milk production through managed changes in herd size and productivity in response to an expected, permanent change in the relative price of milk. Chavas and Klemme estimated supply elasticity to range from 0.22 to 1.17 for this time frame. Ippolito and Masson used estimates of 0.4 to 0.9 in their work. Helmberger and Chen estimated the "long run" milk supply elasticity to be 0.583 , while Chen, Courtney and Schmitz estimated an elasticty of 2.53. We choose a supply elasticity of 1.0 , which is well within the range of estimates used in prior studies.

The milk demand elasticities used to parameterize the model are also drawn from the agricultural economics literature. Estimates of the long run demand elasticity for fluid class milk range from -0.34 (Ippolito and Masson) to -0.076 (Helmberger and Chen). Estimates of the demand elasticity for manufacturing milk range from -0.350 (Helmberger and Chen; Dahlgran) to -0.2 (Ippolito and Masson). Heien and Wessells estimated own-price elasticities of -0.63 for retail demand for milk, -0.52 for cheese and 0.73 for butter. Huang estimated own-price elasticities of -0.26 for retail demand for milk, -0.33 cheese and -0.17 butter. We assume that the elasticity of the national demand for manufacturing milk (at the farm level) is -0.2 . We also assume a regional fluid demand elasticity of -0.2 . Both of these are within the range of estimates used in prior studies. We refer the reader to Johnson et al. for detailed discussion on the theory and practice of demand analysis for milk and dairy products.

Following Ippolito and Masson, the elasticity of the demand for manufacturing milk facing Northeast producers is 


$$
\begin{aligned}
& \eta^{\mathrm{NE}}=\frac{1}{\mathrm{~s}} \eta^{\mathrm{US}}+\left(1-\frac{1}{\mathrm{~s}}\right) \varepsilon^{\mathrm{ROC}} \\
& \eta^{\mathrm{i}}=\text { demand elasticity } \\
& \varepsilon^{\mathrm{ROC}}=\text { rest of the country's supply elasticity } \\
& \mathrm{s}=\text { the Northeast's share of manufacturuing milk production. }
\end{aligned}
$$

In 1999 the Northeast states supplied only 3\% of the nation's manufacturing milk. Given a supply elasticity of 1.0 and a national demand elasticity of -0.2 , the elasticity of demand for manufacturing milk facing the Northeast is -39 .

In the appendix we examine the sensitivity of our results to our assumptions on supply and demand elasticities.

We compare the prices and quantities that prevailed under the Compact regime with the equilibrium prices and quantities that would have resulted from the fixed differential policy of the FMMO. We calculate the New England FMMO fluid differential as the fluid class price announced for the New England FMMO less the imputed manufacturing price. Using this differential, we find the equilibrium prices and quantities without the Compact. Our approach differs slightly from previous studies in that we simulate the class and blend prices that would be announced by the FMMO in the absence of the Compact. Other studies simply use the class and blend prices actually announced, which is not completely accurate since the class and blend prices depend on production, which is effected by the Compact.

The effects of the Compact on Northeast consumers and producers are presented in Table 2. Using 1999 as a base year, we find that the Compact raises the price of fluid 
milk by $\$ 1.20$ per $\mathrm{cwt}^{7}$, or about $7 \%$. The higher fluid class price causes lower sales of fluid milk, costing consumers of fluid milk in The Northeast $\$ 36$ million in consumer surplus.

The higher fluid class price paid under the Compact rules raises the producer blend price, encouraging more production and raising producer revenues. The effect of the Compact on the national price of manufacturing milk is relatively small, with expansion in manufacturing class sales from The Northeast causing a $0.2 \%$ drop in that price.

The Compact affects producers outside of the Compact region (who do not deliver milk to Northeast plants) by lowering the price for manufacturing milk. Producers in other FMMOs receive a blend price as described in the previous section. For convenience, we rewrite the expression for that price here for a single FMMO i:

$$
\begin{aligned}
P_{b i}\left(P_{m} ; d_{i}\right) & =\frac{D_{f i}\left(P_{m}+d_{i}\right)\left(P_{m}+d_{i}\right)+D_{m i}\left(P_{m}\right) P_{m}}{D_{f_{i}}\left(P_{m}+d_{i}\right)+D_{m i}\left(P_{m}\right)} \\
& =P_{m}+\frac{D_{f i}\left(P_{m}+d_{i}\right)}{D_{f i}\left(P_{m}+d_{i}\right)+D_{m i}\left(P_{m}\right)} d_{i}
\end{aligned} .
$$

We can express the blend price equivalently as

\footnotetext{
${ }^{7}$ We actually find the Compact to raise the Class 1 price by $\$ 1.201$ relative to the no-Compact scenario. This is a slightly larger effect than the $\$ 1.20$, which the Compact Commission reports as the Compact premium-average annual Compact fluid class price less the announced New England FMMO fluid class price_-in 1999. We compare the fluid class price paid under the Compact to the fluid class price that would have prevailed under FMMO regulations in the absence of the Compact, given the fixed differential pricing rule used by the FMMO. Our number is bigger due to Northeast producers' supply response to the higher producer price paid under the Compact, which lowers the price of manufacturing milk and thus the FMMO fluid class price.
} 


$$
P_{b i}\left(P_{m} ; d_{i}\right)=P_{m}+s_{i}\left(P_{m} ; d_{i}\right) d_{i},
$$

where $\mathrm{s}_{\mathrm{i}}\left(\mathrm{P}_{\mathrm{m}} ; \mathrm{d}_{\mathrm{i}}\right)$ is the fluid class utilization rate, or the share of total production in region $\mathrm{i}$ that is used in fluid products. Taking the derivative of this last equation with respect to $\mathrm{P}_{\mathrm{m}}$ yields

$$
\frac{d P_{b i}}{d P_{m}}=1+\frac{d s_{i}}{d P_{m}} d_{i}
$$

Further, because manufacturing milk demand is more elastic than fluid demand, $\mathrm{ds}_{\mathrm{i}} / \mathrm{dP}_{\mathrm{m}}$ is positive-for a given fall in the price of manufacturing milk, manufacturing quantity demanded rises by a greater amount than does fluid quantity demanded causing the fluid utilization rate to fall. Thus, a fall in $\mathrm{P}_{\mathrm{m}}$ due to the Compact causes the blend price in other federal orders to fall by more than the change in $\mathrm{P}_{\mathrm{m}}$. But for small changes in the manufacturing milk price we can ignore the change in fluid utilization and approximate the effect on order i's blend price as

$$
\frac{d P_{b i}}{d P_{m}} \approx 1
$$

Thus the two-cent fall in the manufacturing milk price due to the Compact translates into a two-cent fall in the blend price received by producers in other FMMO markets to a very close approximation ${ }^{8}$.

California's milk pricing policy is different than the FMMO system. California uses formulas to set prices for the various milk classes. Descriptions of the California policy can be found in California Department of Food and Agriculture and in Sumner and Wolf. We assume that the formulas used to set the price of manufacturing milk in

\footnotetext{
${ }^{8}$ Note that this approximation underestimates the effect on $\mathrm{P}_{\mathrm{bi}}$ of a change in $\mathrm{P}_{\mathrm{m}}$, and thus underestimates the Compact's effects on producers and consumers in region $\mathrm{i}$.
} 
California reflect the price received for this milk throughout the country. Further, we assume that the formula used to set fluid class prices in California is approximately equal to a fixed differential formula as is used by the FMMO. Then in measuring the effects of the Compact on California producers and consumers, we assume that the two-cent drop in the manufacturing price results in a two-cent drop in all class prices and in the producer price.

The effects of lower manufacturing milk prices on producers outside of the Compact region (who do not deliver milk to Northeast plants) are presented in Table 3. To make the interests of producers more concrete, we show losses to producers in California, Wisconsin and Minnesota—three major milk-producing states (again, using 1999 as a base year). The loss to all producers outside the Compact region (including these states) is also shown in Table 3. We assume a supply elasticity of 1.0 in each state. Northeast milk producers have a small effect on the price of manufacturing milk, costing producers in other states lose about $\$ 62$ million in lost producer surplus, which is less than $1 \%$ of their annual revenues.

The lower manufacturing milk price benefits consumers of that milk. Consumers of manufacturing milk, who accounted for 1,140 million cwt of milk in 1999, gained more than $\$ 22$ million in consumer surplus thanks to the lower manufacturing price due to the Compact. Consumers of fluid milk outside the Compact region also gain from a lower manufacturing milk price. Fluid utilization for the country was about 38\% in 1998 (USDA). Given non-Northeast production of 1,540 million cwt in 1999, fluid consumption outside of the Compact region was 580 million cwt. Thus, fluid milk 
consumers gained nearly $\$ 12$ million in consumer surplus thanks to lower fluid milk prices due to the Compact.

Our results are consistent with those of previous studies. Bailey (1998) assumed a Compact premium of $\$ 2$ per cwt and, thus, finds slightly larger effects on milk prices, although in the same direction as our results. Our results are qualitatively similar to those found by the Office of Management and Budget for an earlier period. Our results are also consistent with those of Nicholson, et al., who provide empirical evidence that the growth in Northeast production is linked to the higher producer price due to the Compact.

\section{Compact Contagion}

Compact contagion refers to the growth of the Dairy Compact movement.

Currently, six additional states may be eligible to join the Northeast Compact, conditional on Congressional consent and the stipulation that a state be contiguous to the current, perhaps expanded Compact region at the time of their entry. The state of New York has already approved participation in the Compact, and awaits Congressional approval. New Jersey and Maryland likewise await Congressional approval, while legislation to join the Compact has been introduced in the Pennsylvania House and Senate. Compact contagion may also come in the form of new compacts formed in other regions of the country. Ten southern states have already approved the formation of a Southern Dairy Compact that could stretch from Kansas to Virginia, and from Texas to Florida. States in the West and Midwest have also shown some interest in forming similar agreements (Compact Commission). 
As the Compact grows to include a larger share of the nation's milk productionand more specifically, of the nation's manufacturing milk production-it will have a larger effect on the national manufacturing milk price. In the previous section, the equation for the elasticity of manufacturing demand facing Compact producers captures this relationship. This demand elasticity is the key parameter determining the Compact's impact on producers and consumers outside the Compact region. As the Compact's share of the manufacturing milk market, s, grows, manufacturing milk demand facing the Compact becomes less elastic. The less elastic is this demand curve, the bigger will be the price effect of a given expansion in Compact manufacturing milk sales on the national market.

To illustrate, we simulate a scenario in which New York and New Jersey join the Northeast Compact. In 1999, the New York-New Jersey (NY-NJ) Federal Milk Marketing Order regulated the sale of 116.60 million cwt of raw milk, of which 46.69 million cwt were used in Class 1 . With $6 \%$ of the manufacturing milk market, the manufacturing demand elasticity facing NY-NJ producers alone is -19 . We assume a supply elasticity of 1.0 to parameterize the NY-NJ milk market.

The addition of the NY-NJ order to the Compact in 1999 would have tripled the Compact's share of the nation's manufacturing milk market from $3 \%$ to $9 \%$. The manufacturing milk demand elasticity for the expanded Compact is -12 (compared to -39 for the Compact without New York-New Jersey).

The average annual Class 1 price for the NY-NJ order was $\$ 16.82$ per cwt in 1999. The average annual blend price was $\$ 14.70$. Assuming that the Compact Class 1 price of $\$ 18.10$ would have prevailed over the expanded Compact region, and assuming a 
Class 1 demand elasticity of -0.2 for the NY-NJ market, NY-NJ producers would have marketed 37.46 million cwt of Class 1 milk at the Compact price. The higher Class 1 price raises the blend price paid to NY-NJ producers, thus inducing an expansion in milk production. Since Class 1 quantity demanded is fixed due to the fixed Class 1 price (and actually lower than Class 1 demand at the lower, non-Compact Class 1 price), the Compact increases the quantity of manufacturing milk sold by the NY-NJ producers.

We simulate the effects of including the NY-NJ market in the Compact by aggregating the NY-NJ and Northeast markets. Total and fluid class quantities from the Northeast and NY-NJ markets are added together, and these quantities are used to compute a weighted average blend price for the expanded Compact region. Table 4 presents the milk prices and quantities for the expanded Compact region, and the effect of removing the expanded Compact.

Under the expanded Compact, fluid consumers in the NY-NJ market must also pay the higher fluid milk price. The effect on these consumers is unambiguous. By raising fluid milk prices to raise dairy farm prices, dairy compacts transfer income from fluid milk consumers to farmers. Consumers of fluid milk within the expanded Compact region lose $\$ 78$ million in consumer surplus.

The effect of Compact contagion nationally is captured in the change in the price for manufacturing milk. Recall that the Compact (without NY-NJ) lowered the national price for manufacturing milk by $\$ 0.02$ per cwt of milk by inducing an expansion of manufacturing milk sales of 236 thousand pounds (see Table 2). The expanded Compact raised manufacturing milk sales by 490 thousand pounds. That is, NY-NJ producers expanded the Compact's manufacturing milk sales by an additional 254 thousand pounds. 
The resulting fall in the national manufacturing milk price is $\$ 0.061-$ more than three times the fall in price induced by the Compact without NY-NJ.

We calculate the effects of the expanded Compact on producers and consumers in the rest of the country, as we did for the original Compact (Table 3), by lowering the average price paid for milk throughout the country by $\$ 0.061$. Results are presented in Table 5. Comparing Table 5 with Table 3, the Compact's effect on those producers who do not enjoy the higher Compact price is more than three times as great when New York and New Jersey are included in the Compact. The expanded Compact's effect on consumers of manufacturing milk is also larger. Manufacturing milk consumers gain nearly $\$ 70$ million in consumer surplus due to the expanded Compact.

Thus, as the Compact grows to regulate a larger share of national milk production, the supply response to the higher producer prices due to the Compact is bigger and has a greater effect on national milk prices. The consequences for those producers not delivering milk to a Compact become greater as the Compact grows ${ }^{9}$.

\footnotetext{
${ }^{9}$ The Northeast Compact recently instituted a supply management program to discourage increased production. Starting in July 2000, $\$ 0.075$ per cwt of all Class 1 milk is to be withheld from the Compact's revenues to create a supply management fund. These funds would then be paid back to those producers who increased production by no more than one percent of the previous year's production. Half of the fund is distributed uniformly to all eligible producers, regardless of an individual farm's level of production. The other half is paid to eligible producers on a per hundredweight basis (Bailey). The supply management scheme does not guarantee success in preventing growth in milk Northeast milk production. If the minimum fluid price set by the Compact is more than $\$ 0.075$ greater than the minimum FMMO price, some producers will find it profitable to increase production. Moreover, the supply management mechanism introduces yet another distortion, giving perverse incentives to Northeast dairy farms by forcing larger and/or growing farms to subsidize smaller farms.
} 


\section{Cartel Stability}

The dairy compact movement raises questions about the organization of government-sponsored cartels. The formation of additional regional compacts in the Southeast and other parts of the country is a distinct possibility. How would the regional administration of regional, independent classified prices affect the FMMO cartel?

It is a well-established result that "cheating" can cause cartel breakdown (Stigler 1964). In the case of the dairy industry, the FMMO has served as enforcer of the implicit agreement among dairy farms across the country. The FMMO system has set and enforced the terms of trade in each order to the benefit of producers in that order and to dairy farmers as a nation-wide group. Because of the commerce clause of the U.S. Constitution, individual states or groups of states face clear limits on authority to operate regional compacts. The compact movement threatens the FMMO cartel by essentially permitting producers in individual regions to legally deviate from the cartel agreement to which the rest of the nation adheres and ignore the effects on producers outside their region.

If each regional compact could enforce its own regional prices, dairy farms in those regions will not suffer from the breakdown of the FMMO cartel. But federal enforcement of the milk cartel is lost in such a scenario, and regional price regulation would seem difficult to maintain if regional blocks are allowed to compete by adjusting differentials independent of the collective choice. That is, individual regional compacts each would adjust classified prices strategically in order to raise local producer revenue, partly at the expense of producers in other regions. One result of this competition is that 
producers in regions with lower fluid utilization rates (i.e. those who lose the most when the price of manufacturing milk falls) will withdraw from the federal cartel. This is exactly what the Upper Midwest producers and their political representatives threatened in 1996 when the FAIR Act included authority for the Northeast Compact.

\section{Conclusion}

The Northeast Dairy Compact raises milk prices for those producers whose milk it regulates. The benefits enjoyed by these producers come at a cost to fluid milk consumers and to producers not receiving the Compact prices. We found that the Compact raised Northeast producer prices by $\$ 0.43$ per cwt., causing an expansion in the Northeast milk supply. Private consumers paid more for fluid milk in The Compact region, and thus reduced consumption. Additional manufacturing milk marketed by Compact producers lowered the price for that milk by $\$ 0.02$ per cwt, resulting in a loss for producers across the country and a gain for consumers of manufactured dairy products.

In giving the New England states authority to form the Compact, Congress recognized states' right to act collectively to regulate the interstate commerce of milk. States in other regions are poised to join the Compact or form additional regional compacts. For the past sixty years, the Federal Milk Marketing Order system has determined the regional pattern of price discrimination for milk in much of the country, preserving those terms of trade by providing disincentives to ship milk across regions. By setting up a separate Compact, the New England states put pressure on the FMMO cartel—raising their own fluid and producer prices, increasing their own production, and 
thus lowering the price to all other producers. Further, by lowering the price to nonCompact producers, the Compact raises the incentive for producers in other regions to form similar pricing arrangements.

Congressional approval of the expansion of the Northeast Compact and of additional regional dairy compacts will increase the share of milk regulated by compacts. The clear losers are private consumers of fluid milk in any compact region. Producers of manufacturing milk and other producers not delivering milk to a compact region are also harmed. Moreover, the compact movement raises again the question of the organization of government-sponsored cartels. Independent, regional administration of regulated milk prices threatens the continued operation of the FMMO system.

Thus the Northeast Compact has potential implications beyond its immediate effects on consumers and producers across the country. This paper provides a framework with which to analyze the implications of the Compact and of compact contagion. 


\section{References}

Alexander, Craig, John Siebert, David Anderson and Ron Knutson, "State Milk Marketing Order Regulation and Interstate Dairy Compacts." Dairy Markets and Policy: Issues and Options No. 0-11, Cornell Program on Dairy Markets and Policy, Oct. 1998. Available online at http://www.cpdmp.cornell.edu/.

Bailey, Ken. Marketing and Pricing of Milk and Dairy Products in the United States. Ames, IA: Iowa State University Press, 1997.

Bailey, Ken. "A Market Analysis of Dairy Compacts Using A Model of Discriminatory Pricing." Paper presented at the 1999 AAEA Summer Meeting, Nashville, TN.

Bailey, Ken. Report on the Operation and Performance of the Northeast Interstate Dairy Compact, 2000. Available online at http://www.aers.psu.edu/dairyoutlook/reports/.

Blaney, Don P., James J. Miller and Richard P. Stillman, Dairy: Background to the 1995 Farm Legislation. Agricultural Economic Report No. 705, U.S. Department of Agriculture, Washington, D.C., April 1995.

California Department of Food and Agriculture, "Dairy Programs" web page. Available online at http://www.cdfa.ca.gov/dairy.

Chavas, J.-P., and R.M. Klemme. “Aggregate Milk Supply Response and Investment Behavior on U.S. Dairy Farms." American Journal of Agricultural Economics, 68(February 1986):55-66.

Chen, D., R. Courtney and A. Schmitz. "A Polynomial Lag Formulation of Milk Production Response." American Journal of Agricultural Economics, 
54(February 1972):77-83.

Dahlgran, R.A. “Welfare Costs and Interregional Income Transfers Due to Regulation of Dairy Markets." American Journal of Agricultural Economics. 62(May 1980):288-296.

Erba, Eric M. and Andrew M. Novakovic. "The Evolution of Milk Pricing and Government Intervention in Dairy Markets.” Bulletin 95-05, Cornell Program on Dairy Markets and Policy, 1995. Available online at http://www.cpdmp.cornell.edu/.

Heien, Dale M. and Cathy Roheim Wessells. "The Demand for Dairy Products:

Structure, Prediction, and Decomposition." American Journal of Agricultural Economics, 70(May 1998):219-228.

Helmberger, Peter and Yu-Hui Chen. "Economic Effects of U.S. Dairy Programs." Journal of Agricultural and Resource Economics, 19(December 1994):225238.

Huang, K. S. U.S. Demand for Food: A Complete System of Price and Income Effects. USDA/ERS Technical Bulletin No. 1714, 1985.

Ippolito, R.A., and R.T. Masson. "The Social Cost of Government Regulation of Milk." Journal of Law and Economics, 21(April 1978):33-65.

Johnson, S.R., D. Peter Stonehouse and Zuhair A. Hassan. Market Demand for Dairy Products. Ames, IA: Iowa State Press, 1992.

Kessell, Reuben. "Economic Effects of Federal Regulation of Milk Markets." Journal of Law and Economics, 10(October 1967): 51-78.

Kwoka, John E., Jr. "Pricing under Federal Milk Market Regulation.” Economic Inquiry. 15(1977): 367-384. 
Manchester, Alden D. The Public Role in the Dairy Economy: Why and How Governments Intervene in the Milk Business. Westview Special Studies in Agricultural Sciences and Policy. Boulder CO: Westview Press, 1983.

Nicholson, Charles F., Budy Resosudarmo and Rick Wackernagel. "Impacts of the Northeast Interstate Dairy Compact on New England Milk Supply.” Paper presented at the 1999 AAEA Summer Meeting, Nashville, TN.

Northeast Dairy Compact Commission, "Northeast Dairy Compact Commission" web page. Available online at http://www.dairycompact.org.

Office of Management and Budget, The Economic Effects of the Northeast Interstate Dairy Compact, A Study Required by Section 732 of the FY 1998 Agricultural Appropriations Act (PL 105-86). Washington, DC, 1998.

Stigler, George J. “A Theory of Oligopoly.” Journal of Political Economy, vol. 72(February 1964):44-61.

Stigler, George J. The Citizen and the State: Essays on Regulation. University of Chicago Press, 1975.

Sumner, Daniel A. and Tom Cox. "FAIR Dairy Policy," Contemporary Economic Policy, 16(January 1998):58-68.

Sumner, Daniel A and Norbert Wilson. "Creation and distribution of economic rents by regulation: Development and evolution of milk marketing orders in California," Agricultural History, 74(Spring 2000):198-210.

Sumner, Daniel A and Christopher Wolf. "Quotas Without Supply Control: Effects of Dairy Quota Policy in California." American Journal of Agricultural Economics, 78(May 2000):354-366. 
U.S. Department of Agriculture, AMS. "Federal Milk Marketing Orders" web page. Available online at http://www.ams.usda.gov/dairy/orders.htm.

U.S. Department of Agriculture, NASS. Agricultural Statistics, various issues. U.S. Department of Agriculture, NASS. Milk Production, Disposition and Income, 1999 Summary.

U.S. Department of Agriculture, AMS, Federal Milk Order Market Statistics, various issues.

Wackernagel, Rick. "Potential Economic Impacts of the Northeast Interstate Dairy Compact on Vermont Dairy Farms." Agricultural and Resource Economic Review, 27(April 1998):53-62.

\section{Wang, Qingbin, Ziiyob Anne, Catherine Halbrendt, Charles Nicholson and}

Jamie Sung. "Impacts of the Northeast Dairy Compact on the WIC Program: Evidence from Boston and Hartford." Published in Milk Market Impacts of the Northeast Dairy Compact: Report to the Northeast Interstate Dairy Compact Commission, Dept. of Community Development and Applied Economics, University of Vermont and Department of Resource Economics, University of Massachusetts, Amherst, November 1999. 
Figure 1. Milk Marketing Order Equilibrium

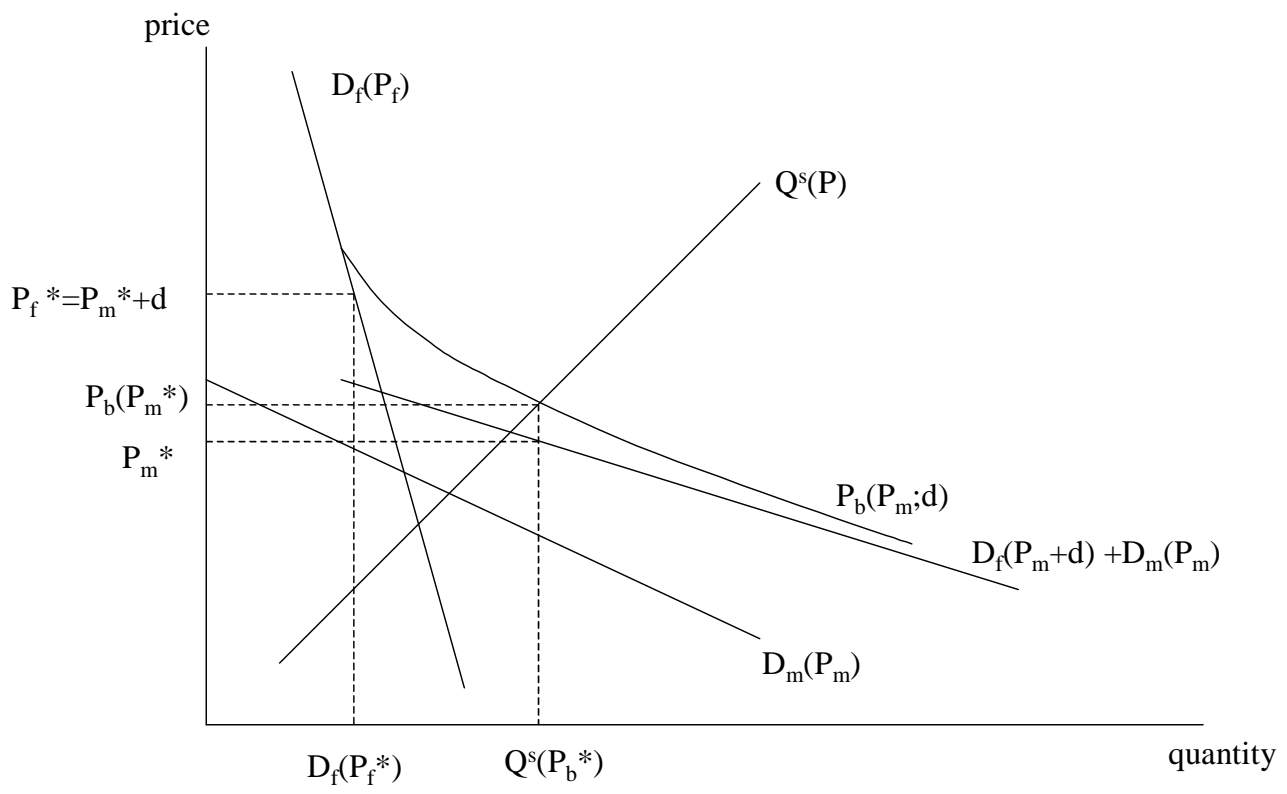


Figure 2. Compact Equilibrium

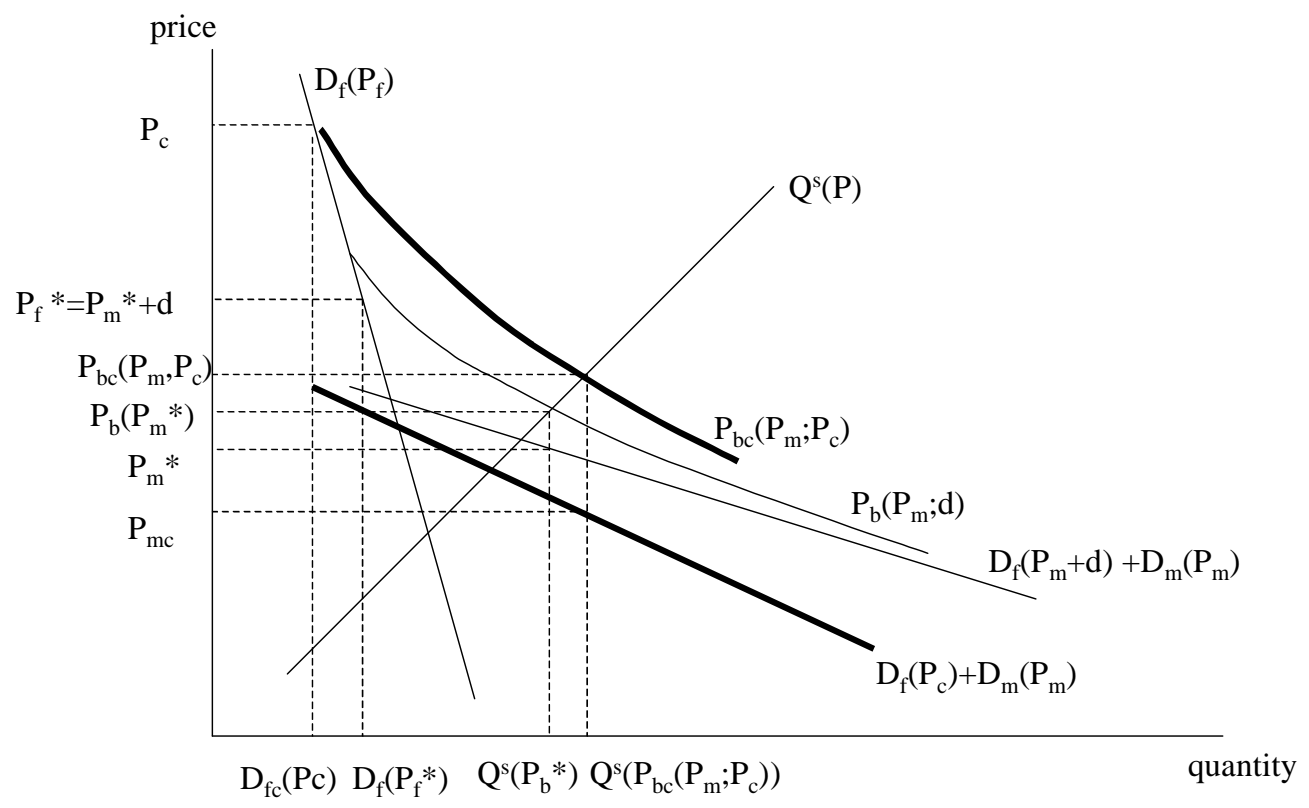


Table 1. Prices and Quantities Used in Base Year Simulations, 1999

\begin{tabular}{|c|c|c|}
\hline & Compact Region & All FMMO \\
\hline & \multicolumn{2}{|c|}{$\$ / \mathrm{cwt}$} \\
\hline Avg Announced FMMO Class 1 price & 16.90 & 16.24 \\
\hline Avg Compact Class 1 price & 18.10 & - \\
\hline Avg Compact fluid premium & 1.20 & - \\
\hline Avg blend price & 14.72 & 14.09 \\
\hline Avg manufacturing price ${ }^{1}$ (imputed) & 11.95 & 12.45 \\
\hline \multirow[t]{2}{*}{ Avg FMMO fluid differential (imputed) } & 4.95 & 3.79 \\
\hline & \multicolumn{2}{|c|}{ milion cwt } \\
\hline Total milk marketed & 66.82 & $1,044.79$ \\
\hline Total Class 1 milk & 30.12 & 452.16 \\
\hline Total manufacturing milk & 36.70 & 592.63 \\
\hline
\end{tabular}

sources: USDA, Compact Commission

(1) The lower price in the Compact region reflects the cost of shipping milk to Boston, MA from interior locations within the Compact region, and not a lower manufacturing milk price relative to the rest of the FMMO. The average Class III price for the New England Order was \$12.44 in 1999. 
Table 2. Effects of Eliminating the New England Dairy Compact*

\begin{tabular}{|c|c|c|c|c|}
\hline & with Compact & w/o Compact & change & \%change \\
\hline \multicolumn{5}{|l|}{ Prices (\$/cwt) } \\
\hline fluid class & 18.100 & 16.899 & -1.200 & -6.6 \\
\hline manufacturing class & 11.946 & 11.966 & 0.020 & 0.2 \\
\hline producer price & 14.720 & 14.290 & -0.432 & -2.9 \\
\hline Compact fluid premium & 1.201 & & & \\
\hline \multicolumn{5}{|l|}{ Quantities (million cwt) } \\
\hline fluid class & 30.12 & 30.52 & 0.40 & 1.3 \\
\hline manufacturing class & 36.70 & 34.36 & -2.34 & -6.4 \\
\hline total & 66.82 & 64.88 & -1.94 & -2.9 \\
\hline \multicolumn{5}{|l|}{ Welfare (\$million) } \\
\hline New England Producer ${ }^{1}$ & & & -28.228 & -0.3 \\
\hline New EnglandFluid Consumer ${ }^{2}$ & & & 36.384 & 0.7 \\
\hline
\end{tabular}

*1999 base year.

(1) Percent change is change in producer surplus as a percentage of total revenues.

(2) Percent change is change in consumer surplus as a percentage of expenditure on fluid milk. 
Table 3. Effect of Eliminating The Compact on Consumers and Producers in other Regions

\begin{tabular}{|c|c|c|c|c|}
\hline & Compact & No Compact ${ }^{1}$ & change $^{3}$ & \%change \\
\hline \multicolumn{5}{|l|}{ California } \\
\hline price paid $(\$ /$ cwt $)$ & 13.45 & 13.47 & 0.02 & 0.15 \\
\hline production (million cwt) & 304.08 & 304.53 & 0.45 & 0.15 \\
\hline revenues (\$ million) & $4,089.88$ & $4,102.05$ & 12.17 & 0.30 \\
\hline \multicolumn{5}{|l|}{ Wisconsin } \\
\hline price paid & 13.86 & 13.88 & 0.02 & 0.14 \\
\hline production & 227.99 & 228.32 & 0.33 & 0.14 \\
\hline revenues & $3,159.94$ & $3,169.07$ & 9.13 & 0.29 \\
\hline \multicolumn{5}{|l|}{ Minnesota } \\
\hline price paid & 13.99 & 14.01 & 0.02 & 0.14 \\
\hline production & 93.73 & 93.86 & 0.13 & 0.14 \\
\hline revenues & $1,311.28$ & $1,315.03$ & 3.75 & 0.29 \\
\hline \multicolumn{5}{|l|}{ U.S. except Compact region } \\
\hline price paid & 14.37 & 14.39 & 0.02 & 0.14 \\
\hline production & $1,567.02$ & $1,569.20$ & 2.18 & 0.14 \\
\hline revenues & $22,518.03$ & $22,580.75$ & 62.72 & 0.28 \\
\hline fluid consumer surplus (\$ mllion) & & & -11.754 & \\
\hline \multicolumn{5}{|l|}{ U.S. manufacturing consumer } \\
\hline surplus (\$ million) & & & -22.899 & \\
\hline
\end{tabular}

Data source: USDA-NASS, Milk Production, Dispostition and Income 1999 Summary

1. "No Compact" scenarios generated by raising price paid by $\$ 0.02$, which follows from the simulation reported in Table 2.

2. Consumer surplus of all manufacturing milk consumers throughout the country.

3. Change in revenues is approximately equal to change in producer surplus. 
Table 4. Effects of Eliminating the New England Dairy Compact, assuming New York and New Jersey are included in the Compact*

\begin{tabular}{|c|c|c|c|c|}
\hline & with Compact & w/o Compact & change & \%change \\
\hline \multicolumn{5}{|l|}{ Prices (\$/cwt) } \\
\hline fluid class & 18.100 & 16.941 & -1.159 & -6.4 \\
\hline manufacturing class & 11.869 & 11.931 & 0.061 & 0.5 \\
\hline producer price & 14.745 & 14.339 & -0.406 & -2.8 \\
\hline Compact premium & 1.159 & & & \\
\hline \multicolumn{5}{|l|}{ Quantities (million cwt) } \\
\hline fluid class & 67.59 & 68.45 & 0.86 & 1.3 \\
\hline manufacturing class & 78.82 & 73.93 & -4.90 & -6.2 \\
\hline total & 146.41 & 142.07 & -4.34 & -3.0 \\
\hline \multicolumn{5}{|l|}{ Welfare (\$million) } \\
\hline Compact producer $^{1}$ & & & -60.880 & -0.3 \\
\hline Compact fluid consumer $^{2}$ & & & 78.834 & 0.6 \\
\hline
\end{tabular}

*1999 base year

(1) Percent change is change in producer surplus as a percentage of total revenues.

(2) Percent change is change in consumer surplus as a percentage of expenditure on fluid milk. 
Table 5. Effect of Eliminating the Compact on Consumers and Producers in other Regions, assuming New York and New Jersey are included in the Compact

\begin{tabular}{|c|c|c|c|c|}
\hline & Compact & No Compact $^{1}$ & change $^{3}$ & \%change \\
\hline \multicolumn{5}{|l|}{ California } \\
\hline price paid (\$/cwt) & 13.450 & 13.511 & 0.061 & 0.45 \\
\hline production (billion lbs) & 30.408 & 30.546 & 0.138 & 0.45 \\
\hline revenues (\$ million) & 40.899 & 41.271 & 0.372 & 0.91 \\
\hline \multicolumn{5}{|l|}{ Wisconsin } \\
\hline price paid & 13.86 & 13.921 & 0.061 & 0.44 \\
\hline production & 227.99 & 228.993 & 1.003 & 0.44 \\
\hline revenues & $3,159.94$ & 318.782 & -2841.160 & -89.91 \\
\hline \multicolumn{5}{|l|}{ Minnesota } \\
\hline price paid & 13.99 & 14.051 & 0.061 & 0.44 \\
\hline production & 93.73 & 94.139 & 0.409 & 0.44 \\
\hline revenues & $1,311.28$ & 132.274 & -1179.008 & -89.91 \\
\hline \multicolumn{5}{|l|}{ U.S. except Compact region } \\
\hline price paid & 14.34 & 14.404 & 0.061 & 0.43 \\
\hline production & $1,450.42$ & $1,456.59$ & 6.17 & 0.43 \\
\hline revenues & $20,804.01$ & $20,981.34$ & 177.33 & 0.85 \\
\hline fluid consumer surplus (\$ million) & & & -34.005 & \\
\hline \multicolumn{5}{|l|}{ U.S. manufacturing consumer } \\
\hline surplus $(\$ \text { million })^{2}$ & & & -69.817 & \\
\hline
\end{tabular}

Data source: USDA-NASS, Milk Production, Dispostition and Income 1999 Summary

1. "No Compact" scenarios generated by raising price paid by $\$ 0.066$, which follows from the simulation reported in Table 4.

2. Consumer surplus of all manufacturing milk consumers throughout the country.

3. Change in revenues is approximately equal to change in producer surplus. 


\section{Appendix}

We examined our simulation results for sensitivity to our assumptions on supply and demand elasticities. The table below shows the change in the national manufacturing price under a range of supply, fluid demand and local manufacturing demand elasticities that can be found in the literature. Assuming that The Northeast produces three percent of the national supply of manufacturing milk, the regional manufacturing demand elasticities of $-35,-39$ and -42 represent a national demand elasticity of $-0.1,-0.2$ and 0.3 , respectively. Each row in the table represents the change in the national price of manufacturing milk for a different level of supply, fluid demand or manufacturing demand elasticities, ceteris paribus. For example, manufacturing milk price changes for the range of supply elasticities all assume fluid demand elasticity of -0.2 and a manufacturing demand elasticity of -39 .

Sensitivity Analysis

\begin{tabular}{cc}
\hline Supply Elasticity & Change in mfg. Pric \\
\hline 0.5 & 0.012 \\
1 & 0.020 \\
2 & 0.032
\end{tabular}

Fluid Demand Elasticity

$\begin{array}{ll}-0.1 & 0.019 \\ -0.2 & 0.020 \\ -0.3 & 0.021\end{array}$

Mfg Demand Elasticity

$-35$

0.022

$-39$

0.020

$-42$

0.018

note: price changes in $\$$ per hundredweight 